\title{
Wnt/ $\beta$-catenin signaling pathway may regulate the expression of angiogenic growth factors in hepatocellular carcinoma
}

\author{
BO QU, BING-RONG LIU, YA-JU DU, JING CHEN, YAN-QIU CHENG, WEI XU and XIN-HONG WANG \\ Department of Gastroenterology, The Second Affiliated Hospital of Harbin Medical University, \\ Harbin, Heilongjiang 150086, P.R. China
}

Received June 17, 2013; Accepted December 17, 2013

DOI: $10.3892 / \mathrm{ol} .2014 .1828$

\begin{abstract}
The Wnt/ $\beta$-catenin signaling pathway plays a key role during hepatocellular carcinoma (HCC) genesis and development. The present study aimed to investigate the effects of the $\mathrm{Wnt} / \beta$-catenin signaling pathway on the expression of angiogenic growth factors involved in HCC. The HCC HepG2 cell line was transfected with small interfering RNA (siRNA) against $\beta$-catenin. After 72 and $96 \mathrm{~h}$, protein was extracted and the expression levels of $\beta$-catenin, matrix metalloproteinase (MMP)-2, MMP-9, vascular endothelial growth factor (VEGF)-A, VEGF-C and basic fibroblast growth factor (bFGF) were detected by western blot analysis. $\beta$-catenin protein expression was inhibited at both time points. Notably, MMP-2, MMP-9, VEGF-A, VEGF-C and bFGF protein expression levels decreased at $72 \mathrm{~h}$ and then increased at $96 \mathrm{~h}$ after transfection. Our results demonstrated that in $\mathrm{HCC}$ cells, the Wnt/ $\beta$-catenin signaling pathway may regulate the protein expression of the angiogenic factors, MMP-2, MMP-9, VEGF-A, VEGF-C and bFGF. These proteins were downstream of $\beta$-catenin signaling and were also regulated by other factors. In conclusion, the Wnt/ $\beta$-catenin signaling pathway may contribute to the regulation of HCC angiogenesis, infiltration and metastasis through regulating the expression of these angiogenic factors.
\end{abstract}

\section{Introduction}

The cytoplasmic protein, $\beta$-catenin, is a central molecule in the Wnt signaling pathway and plays a key role in the genesis and development of tumors. The Wnt/ $\beta$-catenin signaling pathway has been shown to be deregulated in hepatocellular carcinoma (HCC) (1-3), gastric cancer (3), breast cancer (4),

Correspondence to: Associate Professor Xin-Hong Wang, Department of Gastroenterology, The Second Affiliated Hospital of Harbin Medical University, 246 Xuefu Road, Harbin, Heilongjiang 150086, P.R. China

E-mail: yuner1976@126.com

Key words: hepatocellular carcinoma, RNA interference, $\beta$-catenin, signaling pathway, angiogenesis factor and colon cancer $(3,5,6)$. When $\beta$-catenin phosphorylation and ubiquitin-dependent degradation are inhibited, $\beta$-catenin concentrates in the cytoplasm and forms a complex with the transcription factor, lymphoid enhancing factor-1 $\left(\mathrm{LEF}_{1}\right) / \mathrm{T}$-cell factor (TCF), which is subsequently transported into cell nuclei. This transcription complex activates the expression of downstream target genes, resulting in abnormal cell proliferation and cell carcinogenesis (6). To date, several target genes of this signaling pathway have been identified, including c-jun, c-fos, c-myc $(7,8)$, cyclins $(7,9)$, survivin $(7)$ and peroxisome proliferator-activated receptor- $\gamma$. Further research on the target genes of the $\mathrm{Wnt} / \beta$-catenin signaling pathway is required to increase our understanding of the role of this pathway in the genesis and development of tumors.

Research on tumor angiogenic factors was initiated in 1968 (10). To date, a number of crucial angiogenic factors have been isolated, including vascular endothelial growth factor (VEGF), tissue factor, matrix metalloproteinase (MMP), fibroblast growth factor (FGF) and tumor necrosis factor. These factors play crucial roles in tumor angiogenesis, infiltration and metastasis (11-16). Understanding the roles of these angiogenic factors is an active area of research.

Previous studies have identified that the Wnt/ $\beta$-catenin signaling pathway is involved in the regulation of angiogenic factors. It was reported that the $\beta$-catenin pathway regulated the expression of VEGF, MMP-7 and other factors in human colorectal cancer (17). Additionally, in damaged lungs, a correlation between $\beta$-catenin overexpression and increased VEGF expression levels has been demonstrated (18). Moreover, it has been reported that MMP-3 is a direct transcriptional target and a necessary contributor of the Wnt/ $\beta$-catenin signaling pathway (19). Furthermore, Wnt/ $\beta$-catenin signaling influenced the expression of MMP-2 and MMP-9 in T cells (20). However, confirmation of the possible association between the $\mathrm{Wnt} / \beta$-catenin signaling pathway and the expression of angiogenic factors has not yet been fully elucidated.

HCC has a strong tendency to infiltrate and metastasize, and angiogenic factors have key roles in tumor angiogenesis, infiltration and metastasis. Therefore, in the present study, $\beta$-catenin expression was silenced using RNA interference (RNAi) technology in order to examine the association between the Wnt/ $\beta$-catenin signaling pathway and angiogenic factors in HCC. We aimed to further elucidate the role 
of the $\mathrm{Wnt} / \beta$-catenin signaling pathway in the pathogenesis of HCC.

\section{Materials and methods}

Materials. The HCC HepG2 cell line was purchased from the cell bank of the Chinese Academy of Sciences (Guangzhou, China). Lipofectamine ${ }^{\mathrm{TM}} 2000$ was purchased from Invitrogen Life Technologies (Carlsbad, CA, USA). Small interfering RNA (siRNA) directed against $\beta$-catenin was designed and synthesized by the Shanghai GenePharma Co., Ltd. (Shanghai, China). The siRNA sequences were as follows: Sense, 5'-GGGUUCAGAUGAUAUAAAUTT-3'; and antisense, 5'-AUUUAUAUCAUCUGAACCCAG-3'. Dulbecco's modified Eagle's medium (DMEM) with high glucose was purchased from the Shanghai Hecoly Automatic Control Equipment Co., Ltd. (Shanghai, China) and fresh fetal calf serum (FCS) was purchased from TBD Biotechnology Corp. (Tianjin, China). The primary antibodies used were mouse anti- $\beta$-catenin, mouse anti- $\beta$-actin, rabbit anti-MMP- 2 , rabbit anti-MMP-9, mouse anti-VEGF-A, goat anti-VEGF-C and mouse anti-bFGF. The secondary antibodies of horseradish peroxidase (HRP)-conjugated goat anti-rat, goat anti-rabbit and rabbit anti-goat were used. All antibodies were purchased from Santa Cruz Biotechnology, Inc. (Santa Cruz, CA, USA).

Cell culture. HepG2 cells were plated in culture flasks and were cultured in DMEM supplemented with $10 \%$ (vol/vol) fresh $\mathrm{FCS}$ at $37^{\circ} \mathrm{C}$ in a humidified atmosphere with $5 \% \mathrm{CO}_{2}$. Cells were replated when they reached confluency and digested with $0.25 \%$ trypsin for $1 \mathrm{~min}$ in order to maintain the cell line.

Transient transfection. A total of $3 \times 10^{5}$ cells were plated in six-well plates in triplicate and grown to $\sim 30-50 \%$ confluency. For transfection, $500 \mu \mathrm{l}$ of siRNA in Lipofectamine 2000 was added to each well containing cells and $2 \mathrm{ml}$ of DMEM without FCS, and plates were gently rocked back and forth. After $6 \mathrm{~h}$ of transfection, the media were replaced with DMEM containing 10\% (vol/vol) FCS. The cells were harvested after 72 and $96 \mathrm{~h}$, and mRNA and proteins were isolated for further analyses. Control groups without the addition of transfection reagents were also included in this study. All experiments were performed in triplicate and representative results were reported.

Western blot analysis. Cells were lysed in radioimmunoprecipitation assay buffer 72 and $96 \mathrm{~h}$ after transfection for protein isolation (Beyotime, Shanghai, China). Protein concentrations were determined using the bicinchoninic acid assay (Beyotime). Protein samples were electrophoresed on 10\% SDS-PAGE gels ( $\beta$-catenin, MMP-2, MMP-9 and VEGF-C) or 15\% SDS-PAGE gels (VEGF-A and bFGF) and transferred onto polyvinylidene difluoride membranes. The membranes were blocked by incubation in phosphate-buffered saline (PBS) containing $5 \%$ skimmed milk at $37^{\circ} \mathrm{C}$ for $1 \mathrm{~h}$ and then incubated with specific primary antibodies (1:200 dilution) at $4^{\circ} \mathrm{C}$ overnight. The membranes were rinsed three times with PBS, followed by incubation with HRP-conjugated secondary antibodies (1:5,000 dilution) at $37^{\circ} \mathrm{C}$ for $1 \mathrm{~h}$. Membranes were then rinsed three times with PBS and developed in 3,3'diaminobenzidine.
When protein bands were visible on the membranes, color development was discontinued and membranes were rinsed in distilled water. Images were captured by the Gel Imaging system (Tanon Science and Technology Co., Shanghai, China) and images were analyzed by Quantity One software (Bio-Rad Laboratories, Berkeley, CA, USA). The quantitative results of gray-scale analysis were used for the statistical analysis.

Statistical analysis. Data were compared by Student's t-test. $\mathrm{P}<0.05$ was considered to indicate a statistically significant difference.

\section{Results}

Western blot analysis. Protein expression was assessed by western blotting at 72 and $96 \mathrm{~h}$ after the transfection of siRNA against $\beta$-catenin into HCC HepG 2 cells. Our results demonstrated that the expression levels of $\beta$-catenin were decreased after 72 and $96 \mathrm{~h}$, although the levels were slightly higher after $96 \mathrm{~h}$ than those at $72 \mathrm{~h}(\mathrm{t}=4.43 ; \mathrm{P}<0.05)$. MMP-2 and -9 protein expression was inhibited at $72 \mathrm{~h}$, but that of MMP-2 had returned to normal levels after $96 \mathrm{~h}(\mathrm{t}=0.68$; $\mathrm{P}>0.05$ ). MMP-9 expression levels were also increased at $96 \mathrm{~h}$, but were less than the levels observed in the control group $(\mathrm{t}=19.74 ; \mathrm{P}<0.01)$ (Fig. 1). The expression of VEGF-A and -C was inhibited at $72 \mathrm{~h}$ and, although expression increased at $96 \mathrm{~h}$, the levels remained lower than those of the control group $(\mathrm{t}=10.36$ and $\mathrm{t}=15.31$, respectively; $\mathrm{P}<0.01)$. bFGF expression showed a pattern that was similar to that observed for VEGF and MMP, with inhibition at $72 \mathrm{~h}$ and increased expression at $96 \mathrm{~h}(\mathrm{t}=44.11 ; \mathrm{P}<0.01)$ (Fig. 2).

In conclusion, following the transfection of siRNA against $\beta$-catenin into $\mathrm{HCC} \mathrm{HepG} 2$ cells, $\beta$-catenin protein expression was inhibited after 72 and $96 \mathrm{~h}$. MMP-2, -9, VEGF-A, -C and bFGF expression levels were also decreased at $72 \mathrm{~h}$, but began to recover to normal levels at $96 \mathrm{~h}$. Based on these observations, we hypothesized that the expression of these important factors was regulated through the $\mathrm{Wnt} / \beta$-catenin signaling pathway.

\section{Discussion}

RNAi, first reported by Fire et al in 1998 (21), is a gene silencing technique at the post-transcriptional level caused by the introduction of a double-stranded RNA, which induces the degradation of mRNA containing specific homologous sequences (20). To date, RNAi has been successfully applied to the study of gene functions and the associations between the upstream and downstream factors in signaling pathways. RNAi may also potentially be applied in future tumor therapies. The present study identified that the protein expression of $\beta$-catenin was inhibited at 72 and $96 \mathrm{~h}$ after the transfection of siRNA against $\beta$-catenin into HCC HepG2 cells.

Following knockdown of $\beta$-catenin in $\mathrm{HCC}$ HepG2 cells for $72 \mathrm{~h}$, the protein expression levels of MMP-2, -9, VEGF-A, - $\mathrm{C}$ and bFGF also decreased. These findings indicated that the Wnt/ $\beta$-catenin signaling pathway can regulate the expression of these proteins and that they are downstream target proteins of $\beta$-catenin signaling. However, the underlying mechanisms involved in this regulation have not yet been 
A
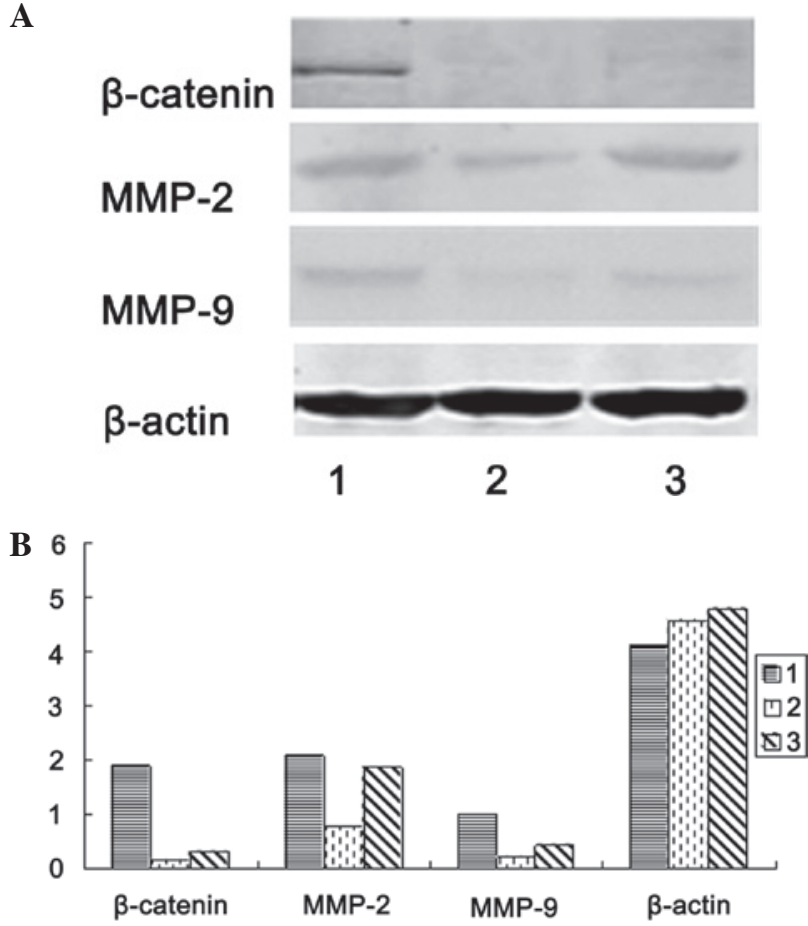

Figure 1. Expression of $\beta$-catenin, MMP-2, MMP-9 and $\beta$-actin after knockdown of $\beta$-catenin by small interfering RNA transfection in hepatocellular carcinoma HepG2 cells. (A) Western blotting of the protein expression in the control group (1), $72 \mathrm{~h}$ after transfection (2) and $96 \mathrm{~h}$ after transfection (3). (B) Protein expression in the control group (1), $72 \mathrm{~h}$ after transfection (2) and $96 \mathrm{~h}$ after transfection (3). Y-axis is the quantitative results of gray-scale analysis. MMP, matrix metalloproteinase.

\section{A}
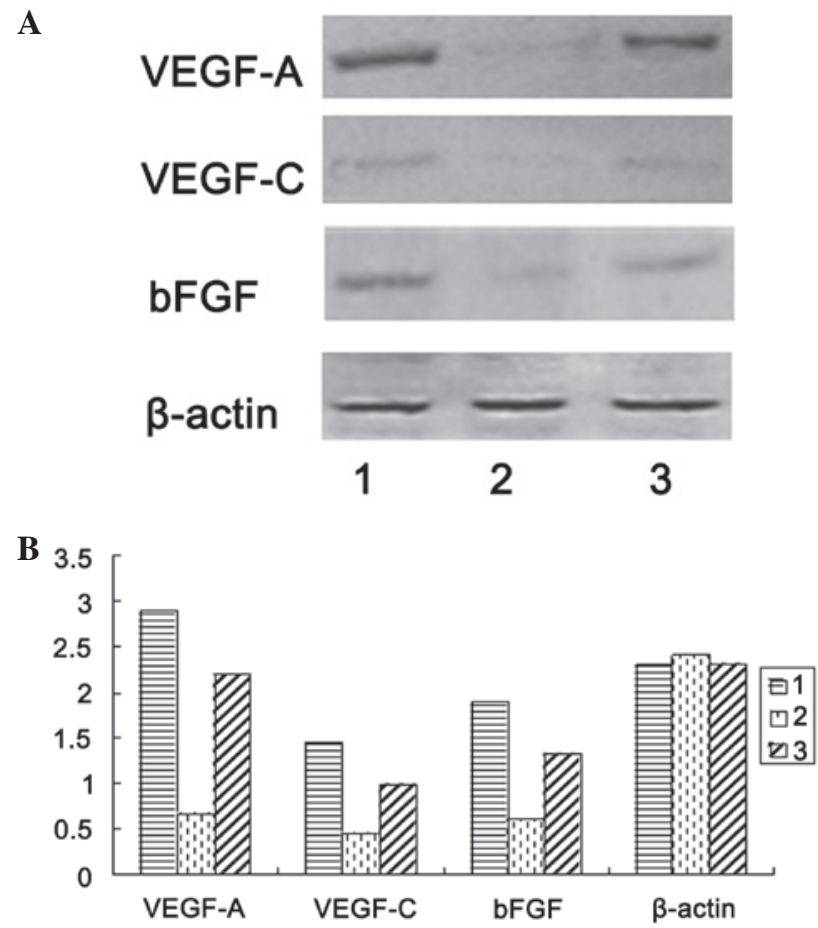

Figure 2. Expression of VEGF-A, VEGF-C, bFGF and $\beta$-actin after knockdown of $\beta$-catenin by small interfering RNA transfection in hepatocellular carcinoma HepG2 cells. (A) Western blotting of the protein expression in the control group (1), $72 \mathrm{~h}$ after transfection (2) and $96 \mathrm{~h}$ after transfection (3). (B) Protein expression levels in the control group (1), $72 \mathrm{~h}$ after transfection (2) and $96 \mathrm{~h}$ after transfection (3). Y-axis is the quantitative results of gray-scale analysis. VEGF, vascular endothelial growth factor; bFGF, basic fibroblast growth factor. fully determined. Previous studies have reported that the Wnt/ $\beta$-catenin signaling pathway acted directly on the MMP promoter through $\mathrm{LEF}_{1} / \mathrm{TCF}$ binding in T cells (20), but this regulatory mechanism has not been reported in HCC and is thus the subject of future investigations in our laboratory.

MMPs promote angiogenesis and contribute to tumor infiltration and metastasis not only through degradation of the extracellular matrix and vascular basilemma, but also through the active regulation of transforming growth factor- $\beta$, bFGF, VEGF and other important signaling molecules. The VEGF family regulated the formation of blood vessels and lymphatic vessels, vascular permeability and endothelial cell survival (23). Moreover, angiogenesis and lymphangiogenesis may promote tumor metastasis. bFGF expression has been correlated with the promotion of cancer cell proliferation and tumor angiogenesis. Additionally, bFGF expression can regulate the activities of collagenase, protease, urokinase-type plasminogen activator and integrins. bFGF also stimulated the secretion of VEGF, another key regulatory factor with synergistic activities. Thus, the $\mathrm{Wnt} / \beta$-catenin signaling pathway contributed to HCC angiogenesis, infiltration and metastasis through regulating the expression of MMP-2, -9, VEGF-A, -C and bFGF.

In addition, MMP-2, -9, VEGF-A, -C and bFGF protein expression levels increased after blocking $\beta$-catenin expression for $96 \mathrm{~h}$ in HepG 2 cells. These results demonstrated that the $\mathrm{Wnt} / \beta$-catenin signaling pathway is not the only factor regulating the expression of these proteins and that a number of other factors are also involved in their regulation. These findings were consistent with other previous studies. Several studies have reported that the STAT3 signaling pathway influenced tumor angiogenesis, infiltration and metastasis by regulating the expression of VEGF, MMPs or bFGF in pancreatic cancer (24), colorectal cancer (25), gastric cancer (26), HCC (27) and several other types of tumors. In fibrosarcoma (28) and colorectal cancer (29) cells, the mitogen-activated protein kinase (MAPK) signaling pathway inhibited the expression of VEGF, bFGF and STAT3, and the p38 MAPK signaling pathway mediated VEGF expression in bone marrow mesenchymal stem cells (29). In addition, $\beta 2$-glycoprotein I inhibited the angiogenesis induced by VEGF and bFGF through the activity of its amino terminal domain (31). In prostate cancer, MMP-2 and -9 expression was regulated by the androgen receptor signaling pathway and was associated with tumor invasion (32). In liver cancer, MMP-2 and -9 expression and activities were upregulated and downregulated by recombinant N-terminal of Sonic Hedgehog ( $\mathrm{SHH}$ ) and the $\mathrm{SHH}$ signaling inhibitor (33). Semaphorin 6A regulated angiogenesis by modulating VEGF signaling (34). Collectively, the multiple pathways that have been reported to participate in the regulation of these angiogenic factors emphasized the complicated regulation of tumor angiogenesis, invasion and metastasis.

In conclusion, this study demonstrated that the Wnt/ $\beta$-catenin signaling pathway contributed to HCC angiogenesis, infiltration and metastasis through regulating the expression of angiogenic factors. The results of the present study require further validation in other cell lines and in animal studies. In addition, the target genes of the Wnt/ $\beta$-catenin signaling pathway and the regulation of angiogenic factors 
have not yet been fully elucidated. Our results aid us to better understand the complex network underlying HCC pathogenesis and provide the basis and methods for multiple aspects of HCC research, including prevention, diagnosis and treatment. With the continual progression of $\mathrm{HCC}$ research, a number of concepts will be updated and bring us closer to curing HCC.

\section{References}

1. Tsao CM, Yan MD, Shih YL, et al: SOX1 functions as a tumor suppressor by antagonizing the $\mathrm{WNT} / \beta$-catenin signaling pathway in hepatocellular carcinoma. Hepatology 56: 2277-2287, 2012.

2. Jiang H, Xia J, Kang J, Ding Y and Wu W: Short hairpin RNA targeting beta-catenin suppresses cell proliferation and induces apoptosis in human gastric carcinoma cells. Scand J Gastroenterol 44: 1452-1462, 2009.

3. Yoo NJ, Kim S and Lee SH: Mutational analysis of WTX gene in Wnt/ beta-catenin pathway in gastric, colorectal, and hepatocellular carcinomas. Dig Dis Sci 54: 1011-1014, 2009.

4. Mukherjee N, Bhattacharya N, Alam N, Roy A, Roychoudhury S and Panda CK: Subtype-specific alterations of the Wnt signaling pathway in breast cancer: clinical and prognostic significance. Cancer Sci 103: 210-220, 2012.

5. Kang YJ, Park HJ, Chung HJ, et al: Wnt/ $/ \beta$-catenin signaling mediates the antitumor activity of magnolol in colorectal cancer cells. Mol Pharmacol 82: 168-177, 2012.

6. Scholer-Dahirel A, Schlabach MR, Loo A, et al: Maintenance of adenomatous polyposis coli (APC)-mutant colorectal cancer is dependent on Wnt/beta-catenin signaling. Proc Natl Acad Sci USA 108: 17135-17140, 2011.

7. Bjorklund CC, Ma W, Wang ZQ, et al: Evidence of a role for activation of Wnt/beta-catenin signaling in the resistance of plasma cells to lenalidomide. J Biol Chem 286: 11009-11020, 2011.

8. Gehrke I, Gandhirajan RK and Kreuzer KA: Targeting the WNT/beta-catenin/TCF/LEF1 axis in solid and haematological cancers: Multiplicity of therapeutic options. Eur J Cancer 45: 2759-2767, 2009.

9. Wang X, Meng X, Sun X, et al: Wnt/ $\beta$-catenin signaling pathway may regulate cell cycle and expression of cyclin A and cyclin E protein in hepatocellular carcinoma cells. Cell Cycle 8: $1567-1570,2009$

10. Tannock IF: The relation between cell proliferation and the vascular system in a transplanted mouse mammary tumour. Br J Cancer 22: 258-273,1968.

11. Li C, Liu B, Dai Z and Tao Y: Knockdown of VEGF receptor-1 (VEGFR-1) impairs macrophage infiltration, angiogenesis and growth of clear cell renal cell carcinoma (CRCC). Cancer Biol Ther 12: 872-880, 2011.

12. Man K, Ng KT, Xu A, et al: Suppression of liver tumor growth and metastasis by adiponectin in nude mice through inhibition of tumor angiogenesis and downregulation of Rho kinase/IFN-inducible protein 10/matrix metalloproteinase 9 signaling. Clin Cancer Res 16: 967-977, 2010.

13. Hu J, Chen C, Su Y, DU J, Qian X and Jin Y: Vascular endothelial growth factor promotes the expression of cyclooxygenase 2 and matrix metalloproteinases in Lewis lung carcinoma cells. Exp Ther Med 4: 1045-1050, 2012.

14. Cole $\mathrm{M}$ and Bromberg $\mathrm{M}$ : Tissue factor as a novel target for treatment of breast cancer. Oncologist 18: 14-18, 2013.

15. Hamed EA, Zakhary MM and Maximous DW: Apoptosis, angiogenesis, inflammation, and oxidative stress: basic interactions in patients with early and metastatic breast cancer. J Cancer Res Clin Oncol 138: 999-1009, 2012.

16. Cattaruzza S, Ozerdem U, Denzel M, et al: Multivalent proteoglycan modulation of FGF mitogenic responses in perivascular cells. Angiogenesis 16: 309-327, 2013.
17. Calviello G, Resci F, Serini S, et al: Docosahexaenoic acid induces proteasome- dependent degradation of beta-catenin, down-regulation of survivin and apoptosis in human colorectal cancer cells not expressing COX-2. Carcinogenesis 28: 1202-1209, 2007.

18. Stockmann C, Kerdiles Y, Nomaksteinsky M, et al: Loss of myeloid cell-derived vascular endothelial growth factor accelerates fibrosis. Proc Natl Acad Sci USA 107: 4329-4334, 2010.

19. Blavier L, Lazaryev A, Shi XH, Dorey FJ, Shackleford GM and DeClerck YA: Stromelysin-1 (MMP-3) is a target and a regulator of Wnt1-induced epithelial-mesenchymal transition (EMT). Cancer Biol Ther 10: 198-208, 2010.

20. Wu B,Crampton SP and Hughes CC: Wnt signaling induces MMP expression and regulates T cell transmigration. Immunity 26: 227-239, 2007.

21. Fire A, Xu S, Montgomery MK, Kostas SA, Driver SE and Mello CC: Potent and specific genetic interference by double-stranded RNA in Caenorhabditis elegans. Nature 391: 806-811, 1998.

22. Hannon GJ: RNA interference. Nature 418: 244-251, 2002.

23. Guo S, Colbert LS, Fuller M, Zhang Y and Gonzalez-Perez RR: Vascular endothelial growth factor receptor-2 in breast cancer. Biochim Biophys Acta 1806: 108-121, 2010.

24. Qiu Z, Huang C, Sun J, et al: RNA interference-mediated signal transducers and activators of transcription 3 gene silencing inhibits invasion and metastasis of human pancreatic cancer cells. Cancer Sci 98: 1099-2006, 2007.

25. Tsareva SA, Moriggl R, Corvinus FM, Wiederanders B, Schütz A, Kovacic B and Friedrich K: Signal transducer and activator of transcription 3 activation promotes invasive growth of colon carcinomas through matrix metalloproteinase induction. Neoplasia 9: 279-291, 2007.

26. Chen J, Wang J, Lin L, et al: Inhibition of STAT3 signaling pathway by nitidine chloride suppressed the angiogenesis and growth of human gastric cancer. Mol Cancer Ther 11: 277-287, 2012.

27. Wang XH, Liu BR, Qu B, et al: Silencing STAT3 may inhibit cell growth through regulating signaling pathway, telomerase, cell cycle, apoptosis and angiogenesis in hepatocellular carcinoma: potential uses for gene therapy. Neoplasma 58: 158-171, 2011.

28. Ding Y, Boguslawski EA, Berghuis BD, et al: Mitogen-activated protein kinase kinase signaling promotes growth and vascularization of fibrosarcoma. Mol Cancer Ther 7: 648-658, 2008.

29. Zhang YH, Wei $\mathrm{W}, \mathrm{Xu} \mathrm{H}$, Wang YY and Wu WX: Inducing effects of hepatocyte growth factor on the expression of vascular endothelial growth factor in human colorectal carcinoma cells through MEK and PI3K signaling pathways. Chin Med J (Engl) 120: 743-748, 2007.

30. Wang M, Zhang W, Crisostomo P, Markel T, Meldrum KK, Fu XY and Meldrum DR: STAT3 mediates bone marrow mesenchymal stem cell VEGF production. J Mol Cell Cardiol 42: 1009-1015, 2007.

31. Yu P, Passam FH, Yu DM, Denyer G and Krilis SA: Beta2-Glycoprotein I inhibits vascular endothelial growth factor and basic fibroblast growth factor induced angiogenesis through its amino terminal domain. J Thromb Haemost 6: 1215-1223, 2008.

32. Hara T, Miyazaki H, Lee A, Tran CP and Reiter RE: Androgen receptor and invasion in prostate cancer. Cancer Res 68: 1128-1135, 2008.

33. Chen JS, Huang XH, Wang Q, et al: Sonic hedgehog signaling pathway induces cell migration and invasion through focal adhesion kinase/AKT signaling-mediated activation of matrix metalloproteinase (MMP)-2 and MMP-9 in liver cancer. Carcinogenesis 34: 10-19, 2013.

34. Segarra M, Ohnuki H, Maric D, et al: Semaphorin 6A regulates angiogenesis by modulating VEGF signaling. Blood 120: 4104-4115, 2012 